\title{
Incidence of Malignancy in Cases of Thyromegaly
}

\author{
Dr.M.Veera Kumar ${ }^{1}$; Dr. N.Subrahmanyam ${ }^{2}$; Dr K Santhaiah ${ }^{3}$ \\ ${ }^{1}$ Associate Professor of ENT, Guntur Medical College, Guntur, India, 9440541799 \\ ${ }^{2}$ Associate Professor of ENT, Guntur Medical College, Vijayawada, India, 9848242280. \\ ${ }^{3}$ Professor of ENT, Guntur Medical College, Guntur, India, 9848134031. \\ Corresponding author: Dr N Subrahmanyam
}

\begin{abstract}
Objectives: This study was done to assess the incidence of malignancy in cases of thyromegaly, the age and sex distribution among them and also the various pathological types of thyroid carcinoma. 65 cases of thyromegaly, who presented to ENT department, Government general hospital, Guntur during a period of two years from January 2015 to January 2017 were selected. All the patients were admitted, investigated thoroughly and treated by surgery. They were then evaluated by histopathological examination.

Materials And Methods: This study was done on 65 patients who presented with thyroid swellings to the department of ENT during a period of two years. All of them were investigated by complete blood chemistry, urine analysis, ECG, chest $x$-ray, 2D echocardiogram, ultrasonography of the neck, Thyroid profile [serum T3, T4, TSH estimation] and FNAC of the thyroid swelling. All the patients were treated by surgery either hemithyroidectomy or total thyroidectomy with preservation of the Parathyroid gland wherever possible. All the excised masses were sent for histopathological examination to know their exact cytological nature so as to arrive at a final diagnosis. Thyroxin supplementation was done post operatively for patients who underwent total thyroidectomy.

Results: This is a prospective study of 65 cases of thyromegaly done at GGH, Guntur during a period of two years. The age of the patients ranged from 22 years to 72 years.

Of the 65 cases, 58 were females [89.23\%] and 7 were males [10.76\%] with a female to male ratio of 8.28:1. Of the 65 cases, 53 were non-malignant [benign] lesions [81.54\%] and 12 were malignant [18.46\%]. Among the malignant cases 10 were Papillary carcinoma cases [83.33\%] and 2 were cases of Follicular carcinoma [16.66\%].

Conclusion: Thyroid swellings are common and may range from simple goitre to benign Adenoma or Carcinoma. The incidence of malignancy in our series is $18.46 \%$. Of the malignant lesions, differentiated tumours are more common and Papillary carcinoma is the commonest. As with all thyroid diseases, carcinoma is also more common in females and in our study the female to male ratio is 5:1. Thyroid malignancy was encountered at all ages but the percentage of incidence was more above the age of 50 years.
\end{abstract}

Key Words: FNAC, Papillary carcinoma, Follicular carcinoma.

\section{Introduction}

The thyroid gland is the largest endocrine gland in the body. It is situated in the neck anteriorly and has two lateral lobes which extend from the thyroid cartilage above to the sixth tracheal ring below. The isthmus joins the two lobes and lies opposite the second to fourth tracheal rings in the midline ${ }^{[1,4]}$. A lateral projection from the isthmus, usually on the left side may be present in some persons and is known as the pyramidal lobe. The thyroid is reddish brown in colour and weighs between 15 to 25 grams ${ }^{[3]}$. It is highly vascular and is invested by the pretracheal fascia. The ligament of Berry firmly attaches the gland to the trachea posteriorly. It is supplied by the Superior thyroid artery [branch of External Carotid] and the Inferior thyroid artery [branch of thyrocervical trunk of Subclavian artery]. The Superior and Middle thyroid veins drain into the Internal jugular vein. The Inferior thyroid veins form a plexus on the trachea and drain into the Brachio-cephalic vein. The lymphatic drainage is to levels $2,3,4,5$ and 7 cervical lymph nodes ${ }^{[1,4]}$.The Superior laryngeal nerves are related to the upper pole of the thyroid lobes and the superior thyroid arteries and the Recurrent laryngeal nerves to the inferior pole and the inferior thyroid arteries. Thyroid swellings are very common and the majority of them are benign. 10 to 20 percent are malignant. Carcinoma of the thyroid is relatively rare ( $1 \%$ of all malignancies $)^{[1]}$ but it is the most common endocrine malignancy $(95 \%)^{[3]}$. It is more common in women with a ratio of 3:1 affecting mainly young people. The most common presentation is a solitary nodule in an euthyroid patient in which the incidence of malignancy varies between 10 to $20 \%^{[1,4]}$. Among the various thyroid malignancies, the most common type is differentiated [80\%] which includes Papillary carcinoma [85\%] and Follicular carcinoma [15\%]. Poorly differentiated carcinoma accounts for $10 \%$ of cases and Medullary carcinoma 5\%. Anaplastic carcinoma, Hurthle cell carcinoma, Lymphoma, Sarcoma, Squamous cell carcinoma and Secondaries in thyroid are very rare ${ }^{[1,2]}$. 
Carcinoma thyroid is a slowly progressive disease and has a favourable prognosis in comparison to other solid tumours. It accounts for less than $0.5 \%$ of deaths due to cancer ${ }^{[1]}$. Out of all types of thyroid carcinomata, papillary carcinoma has the best prognosis while anaplastic carcinoma has the poorest prognosis due to its aggressive nature. Clinical evaluations followed by various investigations, especially FNAC are very important in diagnosing thyroid tumours. Treatment is then planned depending on the histological type. This is mainly surgery i.e., some form of thyroidectomy but can sometimes be multidisciplinary.

\section{History}

Thyroid swellings were first described by the Chinese and Europeans as far back as 2700 BC. Greek physicians considered them as Bronchocoeles or hernias of the wind pipe. Goiter is a French word meaning the throat. Andres Vasalieus [1514 - 1564] first described the thyroid gland. Thomas Wharton [1656] identified the gland and named it as the Thyroid gland due to its relation to the thyroid cartilage. Albert Von Haller classified the thyroid as ductless gland in 1776 but its function was thought to be different.

Galen described surgery for removal of goitre in 200AD. He also described regarding injury to the laryngeal nerves. Roger Frugardi [1170] also performed thyroid surgeries for goitre. He transfixed large goitres with shoe laces so that the ligated mass sloughs. Hieronymus Fabricius Abaquapendente in 1619 recognized that goitres arose from the thyroid gland. Pierre Joseph Default [1791] was the first to perform thyroidectomy by anterior median longitudinal incision and completely removed the gland from the trachea by dissection. Paul Sick [1867] first performed total thyroidectomy and described the symptoms of post-operative thyroid deprivation. Jacque L Reverdin differentiated aponeurotic or surgical capsule from the anatomical capsule.

Theodre Kocher won the Noble Prize [1909] for his observation that thyroid is essential for normal growth, development and metabolism. Duffy [1950] identified the link between irradiation and development of thyroid carcinoma ${ }^{[5]}$. FNAC of thyroid was first described by in the 1930s by Martin and Ellis. Zajicek later described the precise diagnostic criteria ${ }^{[6]}$.

\section{Materials And Methods}

65 patients who presented with thyroid swellings to ENT department, GGH, Guntur, during a period of 2 years from January 2015 to January 2017 were selected for our study of case series. They were of different ages and ranged between 22 to 72 years. They were thoroughly examined clinically and were then admitted into our hospital. All the patients presented with a complaint of swelling in front of the neck as the only symptom. Patients below the age of 20 years and those who were unfit for or refused surgery were excluded from our study as well as cases of thyroiditis. They were then investigated by complete blood chemistry, urine analysis, Thyroid profile [serum T3, T4, TSH level estimation], serum electrolytes, ultrasonography of neck, FNAC of the thyroid swelling, Chest x-ray, ECG and 2D echocardiogram. All the cases were treated by surgery after taking an informed consent. This was either a hemithyroidectomy, subtotal or total thyroidectomy with preservation of at least one parathyroid gland. Those cases who underwent subtotal or total thyroidectomy also recieved oral L-thyroxine replacement therapy post-operatively. The excised masses were then subjected to histopathological examination and the diagnosis confirmed. Of the 65 cases taken up for our study, 53 cases were benign [non-malignant] thyroid swellings [81.54\%] and 12 cases were of malignant nature [18.46\%]. Among these 12 cases, 10 were cases of Papillary carcinoma [83.33\%], 2 were of Follicular carcinoma [16.66\%]. Two patients of papillary carcinoma also had lymph nodal involvement in level 3 cervical nodes and these were excised by modified neck dissection at the time of total thyroidectomy itself. They were then referred for external beam radiotherapy post-operatively.

\section{Results And Observation}

This prospective study was done in 65 patients of thyroid swellings, who presented to ENT department, GGH, Guntur during a period of 2 years. The majority of patients were females, amounting to 58 [89.23\%] in our study [Table No.1]. The rest 7 patients were males [10.76\%]. The female to male ratio is 8.28:1. They were of different ages and ranged between 22 to 72 years [Table No.2]. Benign [non-malignant] lesions were the commonest, amounting to 53 [81.54\%] in our study. 12 cases were of malignant nature [18.46\%], [Table No.3]. Hence, the incidence of malignancy in our series is $18.46 \%$. The sex incidence of carcinoma is 10 females [83.33\%] and 2 males [16.67\%], [Table No.4]. The duration of the swelling ranged from 2 months to 2 years. All the cases presented with the only symptom of swelling in front of the neck. 41 cases presented with swelling of the right lobe of thyroid, 10 cases with left lobe swelling and 14 cases with generalized enlargement of both lobes and isthmus. All the patients were in euthyroid state without any hypothroidism or hyperthyroidism. Among the 53 cases which were nonmalignant, benign solitary nodule was commonest [16 cases], followed by multinodular goitre and follicular adenoma [TableNo.5]. Papillary carcinoma amounted to 10 cases and Follicular carcinoma, 2 cases. Among the cases of papillary carcinoma, 5 were Micropapillary carcinoma, 4 were Follicular variant of papillary carcinoma, 1 was Oncocytic variant of papillary carcinoma and 1 was papillary carcinoma with nodular goitre. It is also observed that the percentage of malignancy increased with age in our series, with a peak above the age of 50 years. 
Table No.1 Showing Sex distrbution

\begin{tabular}{|l|c|c|}
\hline Sex of the patient & No. of patients & Percentage \\
\hline Females & 58 & $89.23 \%$ \\
\hline Males & 7 & $10.76 \%$ \\
\hline
\end{tabular}

Table No.2 Showing age incidence of Thyroid swellings

\begin{tabular}{|l|c|c|}
\hline Age group & No. of patients & Percentage \\
\hline $21-30$ years & 29 & $44.61 \%$ \\
\hline $31-40$ years & 16 & $24.61 \%$ \\
\hline $41-50$ years & 12 & $18.46 \%$ \\
\hline $51-60$ years & 7 & $10.76 \%$ \\
\hline $61-70$ years & 1 & $1.53 \%$ \\
\hline
\end{tabular}

Table No.3 Showing the type of the lesion

\begin{tabular}{|l|c|c|}
\hline Type of lesion & No. of patients & Percentage \\
\hline Benign lesions & 53 & $81.54 \%$ \\
\hline Malignant lesions & 12 & $18.46 \%$ \\
\hline
\end{tabular}

Table No.4 Showing Sex distribution among the lesions

\begin{tabular}{|l|l|l|}
\hline Sex of the patients & Benign lesions & Malignant lesions \\
\hline Females & 48 patients - 90.57\% & 10 patients - 83.33\% \\
\hline Males & 5patients - 9.43\% & 2patients - $16.67 \%$ \\
\hline
\end{tabular}

Table NO.5 Showing Histological nature of the lesion

\begin{tabular}{|l|c|}
\hline Histological type & No. of cases \\
\hline Benign solitary nodule & 16 \\
\hline Multinodular goitre & 13 \\
\hline Follicular adenoma & 12 \\
\hline Colloid goitre & 8 \\
\hline Adenomatous goitre & 2 \\
\hline Adenomatous hyperplasia & 2 \\
\hline Papillary carcinoma & 10 \\
\hline Follicular carcinoma & 2 \\
\hline
\end{tabular}

Table No.6 Showing Malignancy in relation to age

\begin{tabular}{|l|l|l|}
\hline Age group & No. of patients & Percentage \\
\hline $21-30$ years & 4 & $13.79 \%$ \\
\hline $31-40$ years & 3 & $18.75 \%$ \\
\hline $41-50$ years & Nil & ----- \\
\hline $51-60$ years & 5 & $62.50 \%$ \\
\hline
\end{tabular}

PRE-OPERATIVE PHOTOS OF FEW OF OUR CASES

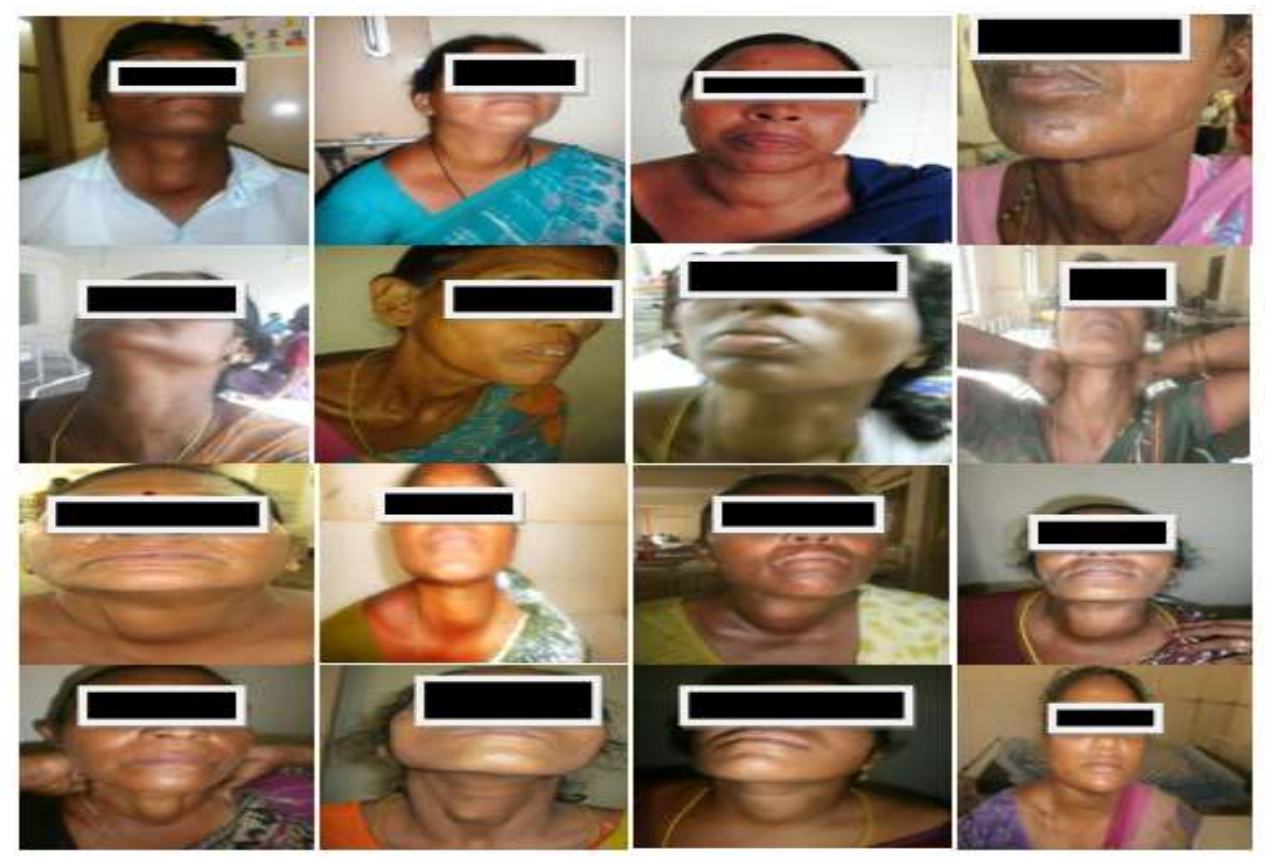




\section{INTRA-OPERATIVE PHOTOS SHOWING RECURRENT LARYNGEAL NERVE}

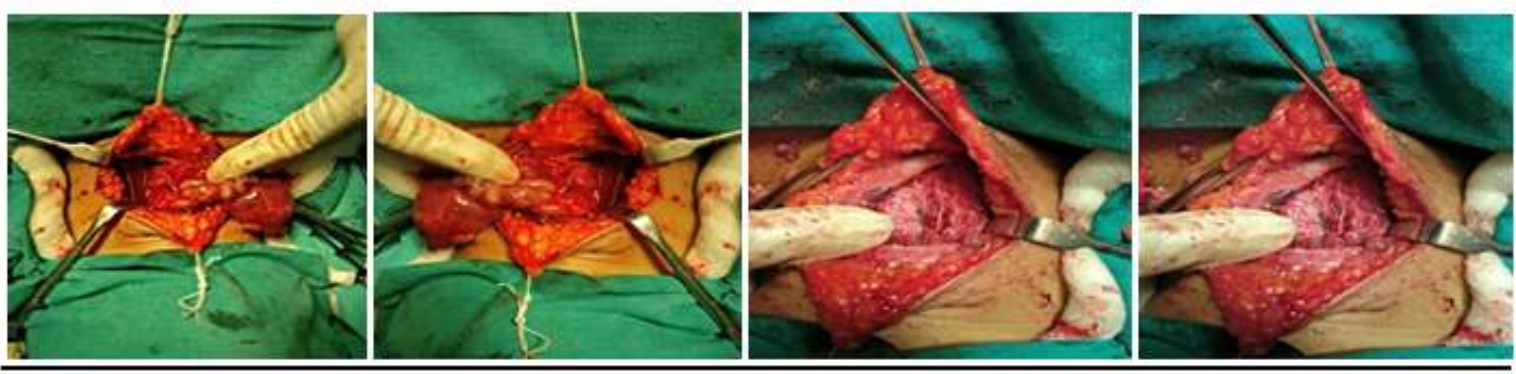

\section{Discussion}

Thyroid swellings are a common problem encountered in otorhinolaryngological practice. Most of the lesions are benign in nature, 53 out of 65 cases, in our study [18.54\%] and carcinoma is present in less than $20 \%$ [12 cases - 18.46\%]. As is well known, thyroid diseases are more common in females [48 cases $-90.57 \%$ ] when compared to males [5 cases - 9.43\%]. This female predominance is observed in malignant cases too - females, 10 cases [83.33\%] and males, 2 cases [16.67\%]. Thyroid swellings are more common in the age group of 21 to 30 years in our study [ 29 cases $-44.61 \%$ ] but the incidence of carcinoma is more common in adults over the age of 50 years. 4 out of 29 cases were malignant in the 21 to 30 years age group [13.79\%] whereas 5 out of 8 cases were malignant above the age of 50 years [62.50\%]. 3 cases occurred in the 31 to 40 years age group [18.75\%]. The incidence of malignancy in our study is estimated to be a little less than twenty percent - $18.46 \%$ [12 out of a total of 65 patients]. Papillary carcinoma is the commonest type of cancer in our series, 10 out of 12 cases $83.33 \%$ and 2(two) cases were follicular carcinoma - 16.66\%. Papillary microcarcinomata were more common, 5 cases followed by Follicular variant of papillary carcinoma, 4 cases. The 2 cases of follicular carcinoma were of encapsulated type.

\section{Conclusion}

From our study, it is evident that thyroid swellings are a common disease with which patients present to Otorhinolaryngology clinics. Most of these are benign in nature and swelling in front of the neck may be the only symptom. Some of them seek medical advice due to cosmetic reason only. Majority of them are females in the young adult age group. Pre-operative FNAC of the thyroid swelling often helps in the diagnosis. Most of these thyromegaly cases are benign in nature and malignancy occurs in 10 to 20 percent of patients. The prognosis for thyroid malignancy is excellent when compared to other solid tumours but one must be vigilant in diagnosing and treating these lesions as early as possible because early diagnosis and treatment provides a near normal life-span to the individual. This is especially so in cases of differentiated thyroid carcinomata which are also the most common, incidentally. The incidence of malignancy in our study was $18.46 \%$ [12 out of 65 cases].

\section{References}

[1]. Scott Brown's Otorhinolaryngology, Head and Neck surgery; 7th edition;2008; James Ramsden, John C Watkinson; 2:2663-2702.

[2]. Ballenger's Otorhinolaryngology, Head and Neck surgery; 17th edition;2009;6; Jan L Kasperbauer, Bryan McIver; 101:1141-1171.

[3]. Cumming's Otorhinolaryngology, Head and Neck surgery;6th edition; 2;Sec 7; 122,123; Stephen Y Lai, Susan J Mandel, Randal S Weber; 1884-1901.

[4]. Stell and Maran's Head and Neck surgery; 4th edition; 23:459-485.

[5]. Kishore S, Edward P, Lawreno AM. Comprehensive text book of Oncology, Baltimore William and Wilkins; 1991;2:1393-1405.

[6]. Stepheeme Regan Michel MC Micholas, Stephent. Eustace Anatomy for diagnosing and imaging; page 5. 